To meet these challenges and achieve these goals, the pediatric neurologist must be trained as a scientist as well as a clinician. Training program directors should encourage fellows with a demonstrated aptitude and motivation in laboratory research. The National Institutes of Health, politicians, and hospital administrators need to provide necessary monies from budget surpluses or through industrial collaboration, allowing residents and young clinicians the time and facilities to pursue projects of research. University Children's Hospitals should be located in close proximity to or within the university complex, permitting frequent discourse and communication of clinician with basic scientist. Time expended in travel between hospital and outlying suburban clinics or the university center is counter-productive. While quantity may be augmented, quality in the standard of service to the patient may be diminished. At this time of escalating health care costs, the realization of these proposals and ideals may appear impractical but, nonetheless, essential, if advances in pediatric neurosciences and "freedom from imperfections" in our patients are to be achieved in the 21st century. J. G. Millichap, M.D., Editor.

COMMENT. My readers and colleagues will have additional and alternative views regarding reasons for celebration of our past accomplishments and challenges for the future. The above comments and views are meant as a basis for further discussion of the pediatric neurologist's role in the year 2000 and beyond.

Special millennium articles written by invited distinguished colleagues in adult neurology are presented by the editors of the Archives of Neurology Jan 2000;57;50-64. Among eighteen presentations, the views and opinions of the pediatric neurologist are sadly lacking. It appears that pediatric neurology, after 50 years progress and development, is still not fully accepted as an equal partner in the neurosciences.

\title{
NEUROBEHAVIORAL DISORDERS
}

\section{STIMULANTS VS BEHAVIOR THERAPY IN ADHD}

A 14-month randomized clinical trial in 579 children, aged 7 to 9.9 years, with ADHD Combined type, compared the effects of four different treatment programs (Multimodal Treatment Study). This cooperative study was performed by 6 independent research teams in collaboration with the National Institutes of Mental Health, and the Office of Special Education, Washington, DC. Treatment assignments were medication alone, psychosocial behavior therapy, combined medication and behavior therapy, and community care. Assessments analysed were ADHD symptoms, oppositional/aggressive symptoms, social skills, internalizing symptoms (anxiety and depression), parent-child relations, and academic achievement in reading, math, and spelling. Behavioral treatment included parent and child training, and school-based intervention. Medication management was methylphenidate (MPH), 28-day, double-blind, daily-switch titration, using 5 repeats of placebo, 5,10 , and 15 or $20 \mathrm{mg}$ t.i.d. The optimal dose of MPH for each subject (average, $38 \mathrm{mg} / \mathrm{d}$ ) was used in subsequent treatment of $73 \%$ of 289 , and an alternative drug (dextroamphetamine (10\%), pemoline (1\%) etc) was prescribed in the remaining patients who failed to respond to MPH.

All 4 groups showed reductions in symptoms of variable degrees during the course of the study. Medication and combined treatment were significantly superior to behavioral treatment and community care in controlling ADHD symptoms. Combined behavioral and stimulant treatment was not superior to medication alone for core ADHD symptoms, but had modest benefits in treating non-ADHD symptoms (ODD etc). Short-term benefits from MPH therapy persist 
during treatment while continued up to 14 months. Total daily doses of MPH in the combined treatment group were lower $(31 \mathrm{mg} / \mathrm{d})$ than in the medication alone group. (Jensen PS and MTA Cooperative Group. A 14-month randomized clinical trial of treatment strategies for attention-deficit/hyperactivity disorder. Arch Gen Psychiatry Dec 1999;56:1073-1086). (Respond: Peter S Jensen MD, Department of Child Psychiatry, Unit 78, NYS Psychiatric Institute, 1051 Riverside Dr, New York, NY 10032).

COMMENT. For the treatment of ADHD, carefully monitored methylphenidate is superior to behavioral therapy and to routine community care, that includes medication. Combined behavioral and stimulant therapies yield no greater benefits than medication alone for core ADHD symptom control, but may provide modest advantages for non-ADHD symptoms, including oppositional behavior and anxiety. One possible advantage of combining behavioral therapy with medication is the reduction in dose of MPH required and the consequent lessening of adverse effects. However, in practice the additional benefits of combined therapy are small and may not warrant the inconvenience and expense to the parents, except in patients who respond only partially to medication. The key to successful medical therapy is frequent monitoring and adjustment of dosage, not always achieved in clinical practice situations.

For a comment on the results of this study from an expert in the UK, see Taylor E. Development of clinical services for attention-deficit/hyperactivity disorder. Arch Gen Psychiatry Dec 1999;56:1097-1099. In the UK, the recognition and treatment of ADHD with medication is not as readily accepted as in the US. Many UK parents will opt for no therapy or behavioral therapy, despite the obvious benefits of MPH demonstrated in this MTA study.

ADHD Genetics. Association of the dopamine transporter gene (DAT1) with poor methylphenidate response is reported from Brookdale University Hospital, Brooklyn, NY (Winsberg BG, Comings DE. I Am Acad Child Adolesc Psychiatry Dec 1999;38:1474-1477). Homozygosity of the 10-repeat allele was found to characterize nonresponse to methylphenidate therapy.

\section{GENETIC TRANSMISSION OF ADHD AND NOCTURNAL ENURESIS}

The transmission of primary nocturnal enuresis (PNE) in relatives of PNE and control probands, with and without $\mathrm{ADHD}$, was examined at the University of California at Los Angeles. Among 126 male probands with and without PNE and ADHD, ages 6-12 yrs, and 338 of their first-degree relatives (237 parents and 101 siblings), the rates of enuresis in parents of enuretic children (40\%) were significantly higher than in parents of non-enuretic control children (6\%), regardless of the co-morbid ADHD of the proband. Of the PNE probands $65 \%$ had at least one affected parent, and of these families, $24 \%$ had an affected sibling. The rates of PNE between parents or siblings in the PNE and PNE + ADHD groups were similar, both groups having significantly elevated rates of PNE in their relatives. In the ADHD only group, there was no familial clustering of PNE. The rate of PNE in first-degree relatives is independent of ADHD in the proband. ADHD and PNE are transmitted independently. (Bailey JN, Ornitz EM, Gehricke JG, Gabikian P, Russell AT, Smalley SL. Transmission of primary nocturnal enuresis and attention deficit hyperactivity disorder. Acta Paediatr Dec 1999;88:1364-1368). (Respond: JN Bailey, University of California at Los Angeles, 760 Westwood Place Box 63, Los Angeles, CA 90024).

COMMENT. The familial nature of nocturnal enuresis is suggested by family 